\title{
Ocupação Pinheirinho: Descrições sobre a influência da trajetória de trabalho de uma ex-moradora em sua escolha por uma ocupação urbana
}

\author{
Pedro Henrique Faria Machado ${ }^{1}$, Elisa Maria Andrade Brisola² \\ 'Doutorando em Ciências Sociais pela PUC-SP, Mestre em Desenvolvimento Humano, Licenciado em Sociologia, Gradua- \\ do em Engenharia Elétrica. \\ ${ }^{2}$ Graduação em Serviço Social pela Universidade do Vale do Paraíba (1984); mestrado e doutorado em Serviço Social \\ pela Pontifícia Universidade Católica de São Paulo (1996 e 2003 respectivamente)
}

Recebido em 29 de outubro de 2016; Aceito em 19 de dezembro de 2016.

\begin{abstract}
Resumo
Este artigo descreve duas cenas distintas, mas inter-relacionadas entre si. A cena 1 apresenta o cotidiano de Irene dentro de uma ocupação urbana conhecida como Pinheirinho, tendo uma lanchonete como posto de observação. Essa cena descreve relações nebulosas, que podem colocar em dúvida o caráter de Irene. Já a cena 2, objetivo deste artigo, descreve a trajetória de trabalho de Irene, anteriormente à ocupação Pinheirinho, contextualizando-o e discutindo a influência deste na opção de Irene pela ocupação. A intenção de apresentar 2 cenas distintas é ressaltar a importância de conhecer o objeto em seu desenvolvimento e em seus diversos aspectos, mediações e ambientes. Acredita-se, dessa maneira, que a cena 2 seja capaz de alterar as impressões iniciais dada pela cena 1. Utilizou-se como fonte primária os relatos obtidos em pesquisa anterior, através da História Oral de Irene, em entrevistas que aconteceram em três momentos distintos, entre janeiro e setembro de 2013.
\end{abstract}

Palavras-chave: Trabalho. Trabalho Precário. Cotidiano. Moradia. Ocupação Urbana.

\begin{abstract}
This article describes two different scenes, but inter-related. Scene 1 presents the Irene's daily life in slum known as Pinheirinho, with a snack bar as observation post. This scene describes relations that can call into question the Irene's character. Scene 2, purpose of this article, describes Irene's works previous experiences in a slum, contextualizing it and discussing those influences on Irene's choice of live in a slum. The intention to present two separate scenes is to highlight the importance of knowing the object in its development and in its several aspects, mediations and environments. Therefore, the scene 2 is able to change the initial impressions given by the scene 1 . It was used as primary source, reports obtained in previous research, by Irene's Oral History, in three interviews between January and September/2013.
\end{abstract}

Keywords: Work. Precarious Work. Everyday life. Housing. Slum. 


\section{INTRODUÇÃO}

\section{CENA 1}

Entrevistador: - Como foi ter uma lanchonete dentro de uma Ocupação Urbana?

Irene ${ }^{1:}$ - [...] Uma correria, mas muito bom [...]!

"Localizada em uma Ocupação Urbana irregular, Irene utilizava de água e luz adquirida de forma ilegal. Pagava em dia seus funcionários informais Entretinha a freguesia com suas máquinas de caça níquel ilegais e mesas de sinuca (pagava uma porcentagem da "ficha" ao dono da mesa), enquanto tomavam cerveja Brahma ou Schin fornecidas por caminhões representantes de grandes empresas, que entregavam na porta de sua lanchonete (assim como o gás e outros pequenos produtos). Nos finais de semana e em datas comemorativas, fazia grandes festas temáticas, inclusive em uma "pracinha" que construiu debaixo de pés de manga, com mesas e cadeiras. Caso o freguês não conseguisse pagar pelo que consumiu, Irene "pendurava" a conta, pois tinha a certeza do pagamento, garantido pelo medo do "sumário" aplicado pelos vizinhos e frequentadores ligados ao PCC ${ }^{2}$. Para manter o "alto nível" da lanchonete, "permitia" que os "nóias" consumissem drogas ilícitas apenas "da metade da rua para lá [da lanchonete]". Caso houvesse uma "batida policial no bar", sua rede de proteção (composta por um sem número de intermediários) a acionava, para que escondesse os caça-níqueis. Certa vez em que foi "pega" com suas máquinas, o policial fez "vistas-grossas". Em outro momento, provavelmente uma denúncia de um X9 da Ocupação, foi "intimada" pela polícia, mas "liberada" pela juíza. Conta que em uma dessas "batidas policiais", encontraram cocaína em uma carteira esquecida no banheiro: "Essa hora tinha em uma parede, uns dez em pé lá [..]. Tinha gente boa, gente ruim, trabalhador, tudo misturado". Então os policiais levaram "[...] um por um. lam e voltavam. Apanharam muito! [...] Teve um neguinho que saiu de lá com a cabeça toda molhada, eu acho que enfiaram a cabeça dele dentro do vaso e deram descarga. [ele gritava]: 'Não, pelo amor de Deus, senhor. Eu sou trabalhador'. [...] Eu fiquei ali [por volta de] meia hora vendo eles apanharem e voltar para o lugar [...] (IRENE)".

O trecho acima lineariza diversos momentos relatados por Irene acerca de sua lanchonete, localizada na Ocupação Pinheirinho, para a pesquisa mestrado de Machado (2014), intitulada "Pinheirinho entre o sonho e a realidade: Experiências em uma Ocupação Urbana na cidade de São José dos Campos - SP".

Este artigo, porém, não tem a lanchonete de Irene como ponto de partida, mas, em última instancia, ponto de chegada ${ }^{3}$. A intenção da cena descrita é permitir ao leitor criar uma primeira imagem dessa muIher, que pode parecer ter caráter duvidoso ou no mínimo "enrolada" e propensa a negócios obscuros. Essa imagem, apesar de viva e dinâmica, se analisada como um recorte estanque no tempo, pode esconder - ou no mínimo, deixar de revelar - a essência de graves questões sociais de nossos tempos. Porém lanni nos lembra Marx (apud lanni, 1979, p. 11): “[...] Toda ciência seria supérflua se a aparência exterior e a essência das coisas coincidissem diretamente".

O objetivo deste artigo, aí sim, seu ponto de partida, é acompanhar a trajetória de trabalho, anterior à ocupação Pinheirinho, relatada através da História Oral de Irene (MACHADO, 2014, p. 65-68), entendendo fatores que a levaram a residir em uma ocupação urbana. Acredita-se, assim, que esse artigo, menos analítico e mais descritivo, trará elementos para o leitor refletir acerca das relações e influencias sobre um trabalhador

1 Irene (nome fictício), cinquenta e quatro anos na época da entrevista, Ensino Fundamental completo e residindo a trinta e quatro anos na cidade de São José dos Campos, pagando aluguel e em situação de coabitação. Residiu na ocupação Pinheirinho de 2004 a 2012. (2013).

2 Facção criminosa Primeiro Comando da Capital. Para mais detalhes sobre a origem e atuação do PCC, consultar Feltran

3 Tal tema merece um artigo à parte. 
comum, podendo comparar essa segunda imagem àquela inicialmente construída.

O mesmo exercício poderia ser realizado com diversos outros sujeitos entrevistados por Machado (2014, p. 37), pois verifica-se que o trabalho ainda mantém um grande peso dentre as múltiplas determinações que levaram cerca de 1700 famílias a residirem na ocupação Pinheirinho.

Para trazer elementos para a construção dessa primeira imagem de Irene - seu ponto de chegada - e uma percepção mínima de todo o simbolismo envolvido nessa escolha, traça-se um breve histórico acerca da ex-ocupação Pinheirinho, desde sua origem, estabelecimento, desocupação e o encaminhamento dado aquela população até se tornarem beneficiários do Programa Minha Casa, Minha Vida. Apresenta-se brevemente a metodologia utilizada e, finalmente, linearizam-se relatos de Irene à respeito de sua trajetória de trabalho, com analises pontuais.

\subsection{BREVE HISTÓRICO DO PINHEIRINHO}

\subsubsection{PERÍODO ANTERIOR A OCUPAÇÃO PINHEIRINHO}

Anteriormente ao estabelecimento da ocupação Pinheirinho, no ano de 2003, alguns moradores, majoritariamente dos bairros que compõem o chamado setor socioeconômico ${ }^{4}$ Campo dos Alemães ${ }^{5}$ (MACHADO, 2014, p. 62), ocuparam um conjunto habitacional vazio da Companhia de Desenvolvimento Habitacional e Urbano $(\mathrm{CDHU})^{6}$, com a justificativa de estarem protestando pela demora na entrega dessas casas aos seus beneficiários (ANDRADE, 2010, p. 71; MACHADO, 2014, p. 29).

Essa primeira ocupação durou pouco menos de um mês, sendo desocupada via reintegração de posse pela Policia Militar. As cerca de 150 famílias, com a liderança de Valdir Martins "Marrom", decidiram então ocupar provisoriamente uma praça pública conhecida popularmente como "Campão", localizada no mesmo setor socioeconômico, enquanto procuravam um terreno mais amplo em que pudessem se estabelecer (ANDRADE, 2010, p. 73; MACHADO, 2014, p. 29).

Após aproximadamente dois meses no "Campão", encontram o terreno da empresa Selecta S/A7 e, considerando-o abandonado, ocuparam-no ano de 2004, já com aproximadamente 240 famílias ${ }^{8}$ (ANDRADE, 2010, p. 72-73; MACHADO, 2014, p. 29). Iniciava-se a ocupação Pinheirinho9 .

4 O setor socioeconômico é um agrupamento de loteamentos ou bairros contíguos que apresentam características socioeconômicas semelhantes. Ao todo, são 24 setores socioeconômicos quem compõe a cidade de São José dos Campos.

$5 \mathrm{O}$ setor denominado Campo dos Alemães agrupa os bairros Campo dos Alemães, Parque dos Ipês, Conj. Hab. Dom Pedro I e II, Conj. Hab. Elmano F. Veloso, Jardim Colonial, Jardim Imperial, Jardim Cruzeiro do Sul, Capitingal, Jardim República, Jardim Nova República e Vila das Flores (NEPO, 2003, p. 11). No ano de 2003 apresentava os piores índices socioeconômicos da cidade, como baixa renda familiar, alta taxa de desemprego, grande adensamento populacional, distância do transporte coletivo e taxa de alfabetização abaixo da média da cidade (NEPO, 2003, p. 20-28). Anteriormente à ocupação Pinheirinho, Irene, residia justamente neste setor socioeconômico.

6 Companhia de Desenvolvimento Habitacional e Urbano do Estado de São Paulo. Empresa vinculada à Secretaria da Habitação. Tem por finalidade executar programas habitacionais em todo o território do Estado, voltados para o atendimento exclusivo da população de baixa renda - atende famílias com renda na faixa de 1 a 10 salários mínimos.

7 Empresa pertencente Naji Nahas, libanês naturalizado brasileiro que fez história no mercado acionário com jogadas de altíssimo risco, sendo considerado o maior investidor individual do Brasil. Sozinho, controlava $6 \%$ dos papéis da Petrobrás e $10 \%$ da Vale do Rio Doce. À época, tais ações valiam US\$ 490 bilhões. Foi protagonista de um dos maiores escândalos do sistema financeiro nacional. Inúmeras acusações de corrupção pesam sobre o megainvestidor (FORLIN; COSTA, 2010, p. 136).

8 Estratégia comum aos movimentos de ocupação urbana, a liderança desta população procurava outras famílias que necessitavam moradias para fazer parte do movimento. Essa estratégia visava dificultar um possível processo de reintegração de posse devido ao número de famílias ocupantes.

9 Recebeu o nome de Pinheirinho, devido aos pinheiros que contornavam um de seus limites (FORLIN; COSTA, 2010, p. 139; 


\subsubsection{A OCUPAÇÃO PINHEIRINHO}

Convencionou-se à época, que a ocupação atenderia à moradia e ao comércio. Assim como acontece em outras áreas periféricas do país, água e a luz eram obtidas através de ligações clandestinas na rede pública. Moravam em barracos de madeira e lona, substituindo-o ao longo do tempo por alvenaria de acordo com a possibilidade de cada morador (FORLIN; COSTA, 2010, p. 139; ANDRADE, 2010, p. 70).

A liderança da ocupação foi organizada com o nome Movimento Urbano dos Sem Teto (MUST - Pinheirinho) e atuava estreitamente ligada ao partido político "Partido Socialista dos Trabalhadores Unificados" (PSTU). Este partido, por sua vez prestava suporte jurídico ao movimento.

Dentro da ocupação ocorriam reuniões setoriais semanais10. As questões levantadas nesses encontros eram discutidas em assembleias gerais, quando também se discutia o andamento do processo de regularização da ocupação, temas gerais que estavam ocorrendo na cidade, regras de convivência, oportunidades de emprego, organização de protestos etc. (ANDRADE, 2010, p. 70; MACHADO, 2014, p. 92). Nessas reuniões, uma cultura política era criada, refletida em diversas manifestações realizadas na cidade de São José dos Campos11.

Desde sua origem, o Pinheirinho era fonte de estigmas e preconceitos por parte da população da cidade, em que se inclui o episódio de notícias que tentavam desqualificar seus moradores, como "a oferta de passagem de ônibus para que famílias retornassem à sua cidade natal", vinculando a ideia que a população residente do Pinheirinho era "estrangeira", ou seja, "de fora de São José dos Campos". Outro exemplo foi a proposta do projeto de lei que propunha o desligamento de todos os programas sociais do Município12 para quem participasse de ocupações (FORLIN; COSTA, 2010, p. 136; MACHADO, 2014, p.115-121).

\subsubsection{A REINTEGRAÇÃO DE POSSE}

A desocupação do Pinheirinho, em janeiro de 2012 (totalizou-se oito anos de ocupação) via reintegração de posse do terreno, ocorreu em meio a longas disputas judiciais. Quando a desocupação parecia eminente, advogados da ocupação e da massa falida Selecta S/A, fizeram um acordo suspendendo a reintegração por 15 dias. Devido ao prazo negociado, moradores mantiveram seus pertences em suas moradias. Porém, após numerosos tramites jurídicos, três dias após o acordo, foi realizada a reintegração de posse com intensa brutalidade.

O amplo aparato policial utilizado merece destaque: dois mil policiais militares, policiais civis, dois helicópteros, carros blindados, 220 viaturas policiais; 40 cães e 100 cavalos sendo utilizados bombas de gás, bala de borracha e spray de pimenta.

Diversos foram os relatos de abusos policiais, violações e prejuízos para aquela população, como pode ser verificado no relatório produzido pelo Conselho Estadual de Defesa dos Direitos da Pessoa Humana - São Paulo (CONDEPE, 2012): ameaça e humilhações; uso indevido de armamentos; pouco tempo para colher os bens; casa demolida sem a devida retirada de bens; agressão física; perda de emprego; dificuldade de livre circulação etc. Tanto a reintegração de posse, quanto sua brutalidade foram rechaçadas por juristas, partidos

ANDRADE, 2010, p. 70).

10 A ocupação Pinheirinho era dividida em 16 setores, cada um sob a responsabilidade de um líder comunitário.

11 Protestavam contra o aumento da tarifa de ônibus na cidade, contra o aumento do salário dos vereadores, suporte à movimentos grevistas etc.

12 A lei Municipal № 6.539, de 26/03/2004, ficou popularmente conhecida entre os ex-moradores da ocupação Pinheirinho como "Lei da Fome”. Não entrou em vigor por seu caráter inconstitucional. 
políticos, defensores dos direitos humanos, movimentos sociais etc13.

Em uma breve reflexão acerca da percepção "positiva" que os moradores da cidade de São José dos Campos tiveram da desocupação14 pode-se supor, ainda superficialmente, que os estigmas e preconceitos dos joseenses com relação à Ocupação Pinheirinho (além da defesa da propriedade privada) acabaram legitimando a brutal ação realizada15.

Após a reintegração de posse, sua população foi transferida para alojamentos improvisados em quadras poliesportivas, enquanto negociavam com a prefeitura da cidade um encaminhamento para suas questões habitacionais e sociais. Acordou-se, por fim que receberiam um auxilio aluguel no valor de $\mathrm{R} \$ 500,0016$, até que moradias fossem destinadas para a eles (TEODORA, 2012, on-line).

\subsubsection{DA REINTEGRAÇÃO DE POSSE AO ANUNCIO DO RESIDENCIAL PINHEIRINHO DOS PAL- MARES}

Só é possível compreender as relações que se estabelecem no pós-reintegração de posse, compreendendo o contexto em que as famílias se depararam ao receber o auxílio aluguel: altos valores de alugueis praticados na cidade; a repentina busca de imóveis por cerca de 1500 famílias impactaram o mercado imobiliário da cidade, elevando os preços dos alugueis; por serem alvo de estigmas e preconceitos, nem todos joseenses concordavam em alugar seus imóveis, pois consideravam ser uma pratica de mercado alugar imóveis apenas para quem "tem o nome limpo" na praça, possuir um fiador e, em muitos casos ter que comprovar renda, limitando as opções de muitos ex-moradores da ocupação Pinheirinho.

Esses breves pontos, permitem a reflexão acerca da impossibilidade que muitos ex-moradores encontraram em conseguir alugar um imóvel, tendo como alternativa recorrer a moradias precárias, à situação de coabitação, abrindo mão do auxílio- aluguel ao se mudarem para outra cidade etc. Algumas famílias acabaram recorrendo a outros imóveis irregulares, inclusive em área de risco17.

Ainda que os ex-moradores da ocupação Pinheirinho tenham se dispersado após a desocupação, fixando-se em diversos pontos da cidade, ou mesmo fora dela, mantiveram reuniões quinzenais, ocorridas no "Campão", a fim de encaminhar soluções para suas questões habitacionais. Dessas reuniões saiu a ideia de realizarem uma ocupação simbólica18, por duas horas, no antigo terreno do Pinheirinho, cobrando dos governos municipal, estadual e federal a construção de suas moradias. Apesar do suporte e envolvimento do PSTU, nesse momento, o líder Marrom já não era mais filiado ao partido.

13 A ação de reintegração de posse contou com manifestações de repudio de Jorge Luiz Souto Maior, Fábio Konder Comparato, Hélio Bicudo, Paulo Sérgio Pinheiro, Gilberto Carvalho, Raquel Rolnik, entidades como a Associação Juízes para a Democracia (AJD) e o Instituto Brasileiro de Ciências Criminais (IBCCRIM), artistas etc. Denúncias de violações de direitos foram feitas à ONU, à Comissão de Direitos Humanos da Ordem dos Advogados do Brasil (OAB), à Comissão de Direitos Humanos da Organização dos Estados Americanos etc. Para mais informações, consultar Borges (2012) e Ação... (2012).

14 Pesquisa realizada pela Agencia Mind, encomendada pelo jornal O Vale (PEREIRA, 2012, on-line), revelou que $54,3 \%$ da população Joseense era favorável à desocupação do Pinheirinho (30,7\% eram contra). Essa aprovação sobe para $72 \%$ dos entrevistados com renda familiar superior a 5 salários mínimos. Apenas $19 \%$ da população identificou como violenta a ação policial.

15 Sobre a criminalização dos pobres e Estado penal, ver Brisola (2012)

16 Auxilio aluguel fornecido pelo governo municipal ( $R \$ 400)$ e estadual $(R \$ 100)$. Para receber o auxílio aluguel foi necessário assinar um termo em que aquela população se comprometia, entre outras coisas, a não realizar outras ocupações.

17 Notícia veiculada no site da Agência Pública relata algumas situações precárias de moradia que se encontram alguns ex-moradores da ocupação Pinheirinho. Disponível em <http://apublica.org/2013/01/familias-de-pinheirinho-sofrem-abandono-sequelas-da-operacao-policial/>. Acesso em 25 out. 2014.

18 Para mais detalhes, ver notícia publicada pelo jornal Brasil de Fato (EM PROTESTO..., 2013, on-line). 
Ao que tudo indica, a organização dos ex-moradores, no pós-desocupação, surtiu efeito, já que, no segundo semestre de 2013, foi anunciada a construção do Residencial Pinheirinho dos Palmares: cerca de 1700 moradias destinadas àquela população, através de uma parceria entre governo federal via "Programa Minha Casa, Minha Vida" 19 (PMCMV) e governo estadual, via "Casa Paulista"20, com previsão de entrega de 1461 moradias em setembro de 2015 (SANTOS, 2014, on-line). Após atrasos nas obras e troca de empreiteira, a nova previsão de entrega das casas é de março de 2016 (ALVES, 2015, on-line). Reuniões quinzenais continuam acontecendo, coordenadas pelo MUST, sob a liderança de Marrom, agora sem o envolvimento direto do PSTU, que assumiu uma posição crítica ao PMCMV.

\section{METODOLOGIA}

As entrevistas com Irene aconteceram em três momentos distintos, entre janeiro e setembro do ano de 2013 (MACHADO, 2014, p. 41) e buscaram reconstruir sua trajetória de vida anteriormente à ocupação. De todos os relatos, fez-se aqui um recorte do que se refere às experiências relacionadas aos seus inúmeros trabalhos.

Hammrsley (apud GROULX, 2012, p. 112) entende que "o que caracteriza um método [...] não é, primeiramente seu objeto, mas sim os procedimentos empregados, os quais devem ser tornados públicos [...]". Nesse sentido, os procedimentos metodológicos empregados neste artigo recorreram a fontes primarias e secundárias, como a pesquisa documental e etnográfica; e a pesquisa bibliográfica.

A História Oral utilizada em Machado (2014), possibilitou uma ampla fonte de dados, dada a riqueza dos depoimentos. Como afirma Cardoso (2004, p. 103): "É neste encontro entre pessoas que se estranham e que fazem um movimento de aproximação que se pode desvendar sentidos ocultos e explicitar relações desconhecidas". Dessa maneira, foi possível linearizar a trajetória de trabalho de Irene, possibilitando inúmeros outros enfoques e analises.

\section{CENA 2: A TRAJETÓRIA DE TRABALHO DE IRENE}

Ainda criança, após o divórcio de seus pais, Irene teve a família separada. Sua mãe continuou morando "na divisa com o [Estado do] Mato Grosso" e ela acompanhou o pai, que se mudou para o Jardim Satélite, Zona Sul da cidade de São José dos Campos, para "trabalhar de faxineiro no CTA"21. Seus irmãos foram morar com outros tios em diferentes cidades.

Com a morte de seu pai, aos "quarenta e oito anos de idade", reencontrou sua mãe e irmãos, com quem dividiu a herança de seu pai. Conseguiu dessa forma "registrar os filhos dela [...], colocar dentadura nela, [porque] ela não tinha mais dentes", além de "outras coisas".

Trabalhou desde cedo. Com 16 anos já tinha carteira assinada na Alpargatas. Teve diversos empregos como babá: "Eu fazia tudo. Eu era baby-sitter, eu era a dona de casa! Elas [as patroas] tinham faxineiras e domésticas. Mas eu era tudo ali [a trabalhadora mais importante" (IRENE). Trabalhou com famílias de "alta classe social", diretores da Ford, AETON, Kodak. "Vivi um bom tempo no meio de americanos". Conta que chegou a negar convite de morar nos Estados Unidos, pelo apego que tinha com o pai.

19 Programa do governo Federal que objetiva estimular o crescimento do mercado formal de habitação e credito, com subsídios aos beneficiários e ampliação de acesso ao financiamento habitacional de longo prazo (MINISTÉRIO..., 2009, p. 192).

20 Braço da Secretaria da Habitação que visa viabilizar a operação dos fundos habitacionais instalados: o Fundo Paulista de Habitação de Interesse Social (FPHIS) e o Fundo Garantidor Habitacional (FGH), ampliando a participação da iniciativa privada e agentes públicos na produção de imóveis para população de baixa renda.

21 Hoje DCTA - Departamento e Tecnologia Aeroespacial. 
Como babá, Irene ajudava as famílias nas atividades do dia a dia: "Eu levava as crianças na escola [...], saia para jantar com a mulher, quando o marido não ia. [..][Ainda que] a família morava [longe de sua casa] [...], eu ia para lá, para eles poderem ir para a reunião social deles, só de americanos". Irene relata que os filhos de "outros americanos" gostavam tanto dela, que pediam autorização para seus pais, para que ela os levassem em seus passeios: "[...] la para o parque [...], restaurante [...]. Eu era confundida até com americana [...] na época"!

Seus patrões não gostavam que ela voltasse para a casa de seu pai quando terminava seu horário de trabalho, pois a queriam cuidando de seus filhos também à noite ou nos finais de semana. Dessa forma, ela os acompanhava nos "lugares chiques que eles iam. [...] só coisa de madame. De vez em quando, eu tirava elas [as] madames e [as] levava para os lugares mais feios". Irene guarda recordações positivas dessa época, como "[fazer] muita amizade". Porém, finaliza esse tema de forma abrupta: "[...] depois acabou".

É interessante se atentar para alguns pontos da fala de Irene, compreendendo as sutilezas do trabalho precário que por vezes passa desapercebido. Trabalhando como babá, suas funções não eram bem definidas, sendo seu trabalho regido pelas necessidades imediatas de seu patrão. Subjetivamente, era transmitida a ideia de incorporação de Irene à família, o que pode justificar seu pronto atendimento às necessidades de seus patrões. Nunca, porém, deixou de se tratar de uma relação trabalhista. A frase "eu era até confundida com americana na época" resume bem a autoimagem criada por Irene. Porém a face do trabalho precário se apresenta em outro momento de seu relato "[...] depois acabou", ou seja, quando os serviços de Irene não foram mais necessários, encerrou-se o contrato de trabalho - quando houvesse. Outro ponto que merece destaque é que, apesar da autoimagem de "ser confundida com uma americana" ou de fazer parte daquela família, sua condição financeira, fruto daquele trabalho, era imensamente inferior à da família, tanto que diz "De vez em quando, eu tirava elas [as] madames e [as] levava para os lugares mais feios", ou seja, mais comuns ao seu meio.

Devido a um acidente de trabalho, perdeu um namorado, com quem teve um relacionamento de 13 anos e uma filha. Conta que ele trabalhava em uma estiva e morreu vítima de um maremoto que ocorreu na cidade de Santos -SP. Não recebeu nenhuma indenização, também pela informalidade do trabalho de seu companheiro.

Anos mais tarde, foi morar com outro namorado, com quem "construiu um patrimônio grande". Com a separação, acabou "perdendo tudo", pois não tinha "nada no meu nome" e ele "era alcoólatra e viciado em cash bingo 22". Com ele teve a experiência de ter um bar "muito grande".

Relata que trabalhou na Alpargatas, "[...] Johnson \& Johnson: na [...] National"23, fui auxiliar de escritório". Acreditava que tantas mudanças se davam por ser "aventureira". Conta que devido aos trabalhos que tinha, morou em diversas cidades, como São Paulo e Campos do Jordão: "[..] Fui trabalhar de doméstica lá".

Trabalhou "uns tempos de faxineira" e seu último contrato, onde trabalhava apenas três dias da semana, foi temporário. Para os dias em que não trabalhava de faxineira, montou um "carrinho de lanche na varanda [...] da casa que pagava aluguel". Com esse carrinho de lanche, "eu pagava o aluguel e sobrevivia disso". Devido à sua melhora de condição financeira, suas filhas foram morar com ela. Aproveitou um quarto de sua casa e montou um brechó: "Separei tudo: infantil, adulto, camisa, calça: eu costuro. [...] Ai, tudo o que tinha estragado, eu costurava, eu lavava, eu passava". Dessa maneira, com o contrato de faxineira já encerrado, "trabalhava [no período da noite] com lanche e durante o dia eu tinha o brechó".

Tendo tido a experiência de costura com o brechó, mais tarde foi trabalhar como "ajudante" em uma

22 Máquinas ilegais de jogos de azar, em que se aposta dinheiro.

23 Atual Panasonic, na via Dutra. 
fábrica de costura: "Eu cortava com a tesoura coisinhas para as costureiras pregarem". Logo "cresceu" dentro da fábrica se tornando líder das costureiras. No total, trabalhou na fábrica por sete anos, abandonando, por falta de tempo, o carrinho de lanche e o brechó que tinha em sua casa.

A fábrica, por sua vez, enviou o setor de estamparia e costura para São Paulo, "Que era tudo [a maior parte da empresa]", ficando em São José dos Campos "só a costura". Dessa maneira, Irene, como líder das costureiras, por diversas vezes tinha que se deslocar para São Paulo "para pôr ordem no corte". Algumas vezes ia "para ficar uma semana", sendo que chegou a ficar "mais de um mês [seguido por] lá". Conta que "na época de muitos pedidos" emendava diversos turnos "Eu cheguei a perder a noção de dia [e noite]".

Em época de "muito serviço", era responsável por recrutar, a pedido da direção da empresa, seus companheiros de trabalho para trabalharem aos domingos. Era um trabalho/turno "Por fora da carteira [de trabalho]. Na hora. Acabou? Vamos embora! Toma o seu dinheiro"! Além de convencer seus companheiros, negociava "com os patrões" quanto pagariam por aquele final de semana: "[...] [a patroa] só oferecia $R \$ 35,00, R \$ 40,00$ estourando, por dia. Eu fazia um motim, eu sempre fui muito do [lado do] empregado [...] nós [Irene e a 'dona da empresa'] brigávamos de quebrar o pau dentro do escritório". Com suas negociações, conseguia aumentar consideravelmente o número de funcionários dispostos a trabalhar no final de semana: "virávamos a noite trabalhando [...]". Se algum se seus companheiros não suportasse o turno de trabalho, Irene tinha a resposta na ponta da língua "Filha: [se] quer vem, não quer não vem [trabalhar]"! Para quem ficava, ela mesma se encarregava de "fazer a janta [...] eu fazia de tudo"!

Por considerar que seus rendimentos não eram satisfatórios e que "meu salário não dava para fazer uma coisa assim [adquirir uma moradia]", Irene decide se mudar para a Ocupação Pinheirinho, vendo nela uma opção para reduzir seus custos. Passado um período com esse forte ritmo de trabalho, tendo que se deslocar para São Paulo e muitas vezes tendo que ficar por lá, acabou pedindo demissão: "eu fiz acordo com eles [os patrões]. Perdi quase a metade do que eu tinha direito [...]". "Empatou" o dinheiro da demissão para a construção de uma lanchonete dentro da Ocupação Pinheirinho, devido à sua experiência anterior com um bar e com um carrinho de lanche. Seu filho caçula vendeu seu fusca e aplicou metade do dinheiro em "material" para auxiliá-la nessa construção.

A precariedade de seus contratos de trabalho - quando existiam - e relações trabalhistas, definiram um ponto de inflexão, limitando suas alternativas e escolhas, traçando estratégias de acordo com o "momento" vivido, a urgência e experiências anteriores. Ao se aproximar de trajetórias como essas, concorda-se com Telles (2010, p. 111), que entende que "Seguir os traçados das mudanças (e conturbações) do mundo urbano significa levar a sério processos e práticas que só se deixam ver nos deslocamentos e nos pontos de inflexão, de entrelaçamento, e bifurcações que vão compondo as realidades urbanas".

\subsection{TRAJETÓRIA E CONTEXTO}

A trajetória de vida de Irene anteriormente à ocupação Pinheirinho, inegavelmente, é marcada pela precariedade de seus inúmeros trabalhos, muitas vezes regidos ao acaso de seus patrões ou de seus frágeis contratos de trabalho. É possível, nessa descrição, encontrar elementos que nos faz compreender e compor melhor a Cena 1 anteriormente descrita. $O$ acumulo de experiências profissionais de Irene reflete diretamente em seus empregos futuros. A experiência, por exemplo, de administrar um bar com um de seus namorados (viciado em "cash-bingo" - outro elemento constante em sua lanchonete do pinheirinho) "capacita-a" a "gerir" um carrinho de lanche em sua casa, o que mais tarde viria a ser seu ganha pão na ocupação Pinheirinho, com uma lanchonete. Ou mesmo seu último trabalho em uma confecção, sendo possível a partir de sua experiência anterior consertando roupas para o seu brechó ${ }^{24}$.

24 Em Machado (2014, p. 83), Irene conta que além da lanchonete, também possuía um brechó dentro da ocupa- 
Alguns dados da cidade de São José dos Campos - SP, ajudam a compor o contexto de Irene. Se em um primeiro momento, a cidade "se faz vitrine", pelo seu elevado PIB - oitavo maior do estado de São Paulo - (O PIB..., 2011) e seu consolidado polo (PDDI-2006, 2006, p. 21, 37), por outro, esconde em seus bairros e loteamentos afastados a desigualdade de renda da cidade, como pode ser verificado na Tabela 1- Rendimento nominal mensal (Pessoas de 10 anos ou mais de Idade):

\begin{tabular}{|c|c|c|c|c|c|c|c|c|c|}
\hline \multirow{2}{*}{$\begin{array}{l}\text { Mesorregiões, } \\
\text { microrregiôes, } \\
\text { municípios, } \\
\text { distritos e bairros }\end{array}$} & \multirow{2}{*}{$\begin{array}{l}\text { Total } \\
\text { (1) }\end{array}$} & \multicolumn{8}{|c|}{ Classes de rendimento nominal mensal (salário mínimo) (2) } \\
\hline & & $\begin{array}{l}\text { Sem } \\
\text { renda (3) }\end{array}$ & $\begin{array}{l}\text { Até } \\
1 / 2\end{array}$ & $\begin{array}{l}\text { Mais de } \\
1 / 2 \text { a } 1\end{array}$ & $\begin{array}{l}\text { Mais } \\
\text { de } 1 \\
\text { a } 2\end{array}$ & $\begin{array}{l}\text { Mais } \\
\text { de } 2 \text { a } \\
5\end{array}$ & $\begin{array}{l}\text { Mais } \\
\text { de } 5 \text { a } \\
10\end{array}$ & $\begin{array}{l}\text { Mais } \\
\text { de } 10 \text { a } \\
20\end{array}$ & $\begin{array}{l}\text { Mais } \\
\text { de } 20\end{array}$ \\
\hline São José & 544.0 & 194.930 & 8.340 & 67.038 & 123.6 & 96.373 & 34.889 & 13.645 & 4.500 \\
\hline $\begin{array}{l}\text { Campos } \\
\%\end{array}$ & $\begin{array}{l}32 \\
100 \%\end{array}$ & $36 \%$ & $2 \%$ & $12 \%$ & $\begin{array}{l}89 \\
23 \%\end{array}$ & $18 \%$ & $6 \%$ & $3 \%$ & $1 \%$ \\
\hline
\end{tabular}

Fonte: IBGE, 2010 (elaboração própria)

(1) Inclusive as pessoas sem declaração de rendimento nominal mensal. (2) Salário mínimo: $\mathrm{R}$ 510,00. (3) Inclusive as pessoas que recebiam somente em benefícios.

Percebe-se que o "desenvolvimento" da cidade não atinge a todos, a partir do momento que a renda é má distribuída entre seus habitantes, onde $50 \%$ da população com 10 anos ou mais de idade vivem com até um salário mínimo (72\% com até 2 salários mínimos).

A importância desses dados ganha mais relevância quando se reconhece que na cidade de São José dos Campos, em três anos, "o preço de imóveis na região subiu 110\%. A média de preço do metro quadrado, que em 2008 era de $R \$ 1.900$, passou para R\$ 4.000 em 2011" (COSTA, 2012, on-line), mesmo com índices, como o da construção civil ou da inflação sem seguir a mesma tendência.

Interessante verificar que o perfil dos moradores da ocupação Pinheirinho, destino de Irene, segue a mesma tendência de precariedade de trabalho por ela relatado. Em pesquisa realizada no ano de 2006, Forlin e Costa (2010, p. 147-148) identificaram que 60\% das moradias possuíam rendimento de até um salário mínimo ( $R \$ 350,00$ na época) e outros 32\% entre um e meio a dois salários mínimos, com as principais atividades relacionadas na Figura 1 - Atividades geradores de renda:

Figura 1 - Atividades geradores de renda

ção Pinheirinho. 


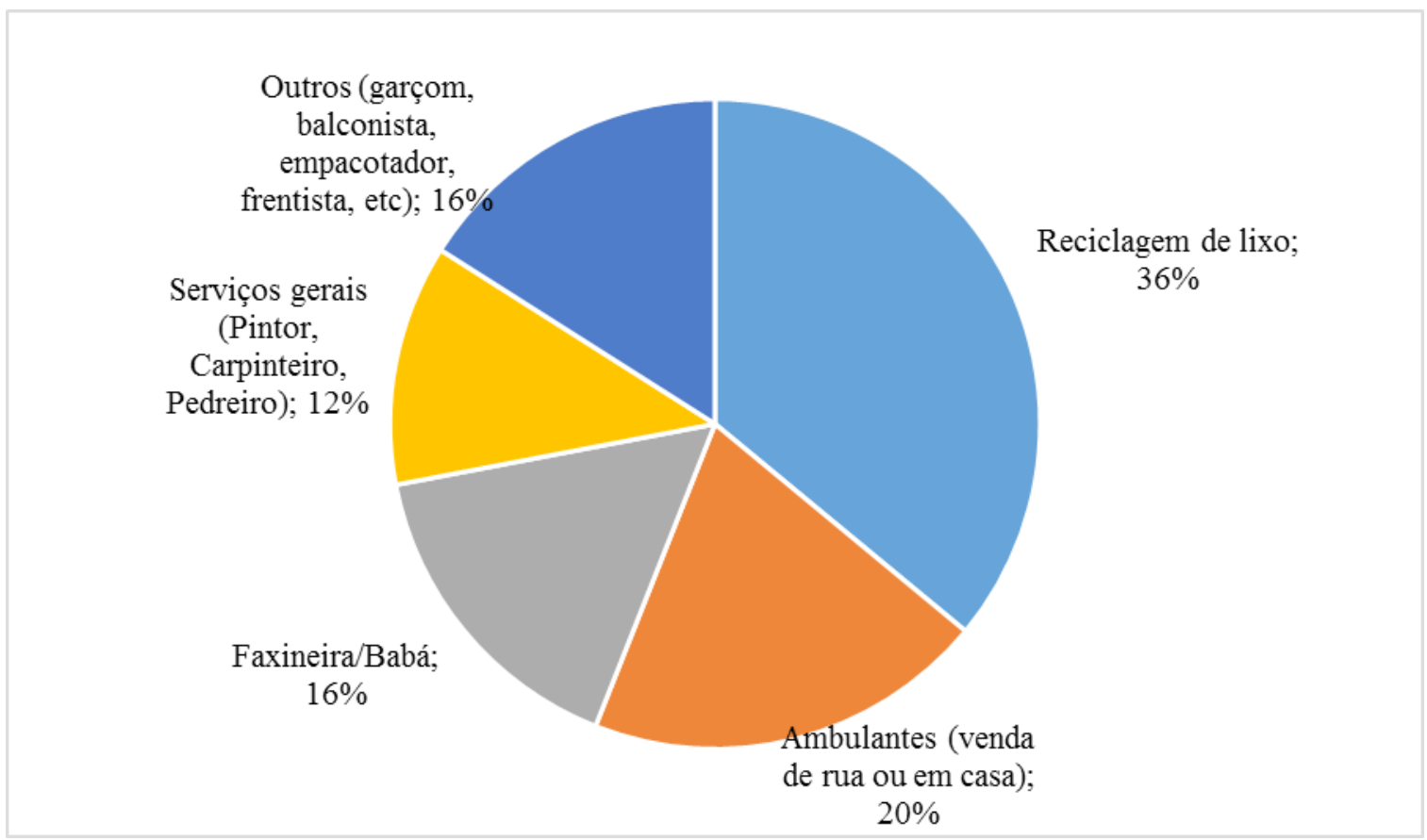

FONTE: Forlin e Costa (2010, p. 147-148) (elaboração própria)

As configurações dos inúmeros trabalhos de Irene, o chamado "trabalho informal" e as baixas remunerações, encontram-se ancoradas no que Antunes (2004) define como as mutações do mundo do trabalho. Ainda nesse sentido, Forlin e Costa identificaram (ibidem, p. 147) que no ano de 2006, 76\% dos domicílios dentro da ocupação Pinheirinho não possuíam nenhum membro com carteira assinada.

\subsection{AS MUTAÇÕES DO MUNDO DO TRABALHO ${ }^{25}$}

O mundo do trabalho, nos últimos trinta anos, sofreu grandes mudanças e muito se discute a seu respeito, com questionamentos no sentido de seu esgotamento, assim como da própria classe trabalhadora. Trata-se, ainda, de uma categoria importante como força estruturante da vida social?

Acredita-se que para tal análise, seja necessário ajustar o foco para essa questão, uma vez que ao utilizar referenciais do modelo fordista/taylorista ou de seu ideário, pode-se perder de vista como o trabalho se apresenta nos dias de hoje, em constante "mutação", para utilizar a definição de Antunes (2004, p. 335).

Se, por um lado, é preciso ajustar o foco, por outro, seguindo as pistas de Telles (2010, p. 95), não é de se estranhar encontrar novas configurações societárias a partir dessas transformações. Antunes (idem, $p$. 335), a esse respeito, afirma que a "classe trabalhadora não é idêntica àquela existente em meados do século passado, ela também não está em vias de desaparição". É preciso atentar que a flexibilização do contrato de trabalho, o trabalho sem forma, informalizado, acaba redefinindo as relações de classe, direitos e relações sindicais, distanciando-se dos modelos dos "tempos fordistas" (TELLES, 2010, p. 84; OLIVEIRA, 2007, p. 27).

Antunes (idem, p. 336), em suas análises sobre as mutações no mundo do trabalho, considera que a "classe-que-vive-do-trabalho", ou seja, "homens e mulheres que vivem da venda de sua força de trabalho" e são "despossuídos dos meios de produção", vivem mudanças, as quais afetam sua condição de vida e trabaIho. Nesse sentido, identifica-se no depoimento de Irene, uma trajetória de vida extremamente relacionada com a sua vida profissional, porém, como traz Oliveira (2007, p. 27): “Tal é a contrarrevolução de nosso 25 Título que faz alusão ao artigo de Antunes (2004). 
tempo. A sociabilidade plasmada na época do trabalho como categoria central, do trabalho fixo, previsível a longo prazo, base da produção fordista e do consenso welfarista, dançou".

Para Antunes (idem, p. 343), a classe trabalhadora é "mais ampla que o proletariado industrial produtivo do século passado, embora este ainda se constitua em seu núcleo fundamental". Ressalta que é preciso uma compreensão mais ampliada do trabalho e de suas mudanças para entendê-la.

São mudanças referentes ao modelo taylorista e fordista. Nesse novo modelo, o proletariado industrial, fabril, tradicional, manual, estável e especializado, com o advento da reestruturação produtiva, motivada pela introdução de máquinas informatizadas, dá lugar a formas desregulamentadas do trabalho, trazendo instabilidade aos trabalhadores. Outra tendência é caracterizada pelo aumento do novo proletariado fabril e de serviços, que cresce em escala mundial, estando presente nas mais diversas modalidades de trabalhos precarizados, na forma de trabalho temporário, terceirizado, subcontratado, informalizado, part-time etc. e no próprio desemprego em si (ANTUNES, ibidem, p. 336-341).

Antunes (ibidem, p. 336-341) ainda aponta outras mudanças no mundo do trabalho, como o incremento do chamado "terceiro setor", de teor comunitário, motivados por trabalhos voluntários, de caráter assistencial, sem fins diretamente mercantis ou lucrativos, comumente encontrados à margem do mercado, como as Organizações Não Governamentais (ONGs) e outras associações. A esse respeito, o autor considera positivo o caráter do terceiro setor de reintegração dos trabalhadores expulsos do mercado de trabalho formal, trazendo alento ao trabalhador que não se vê completamente excluído, por estar "realizando atividades efetivas, dotadas de algum sentido social e útil". Porém, pondera que essas atividades são funcionais ao sistema capitalista, "que se mostra completamente incapaz de absorver os desempregados e precarizados". Se o autor considera positivo o caráter de "minimizador do desemprego estrutural", considera insuficiente como um efetivo transformador social, "capaz de alterar o sistema de capital em sua lógica", apesar de suprir algumas lacunas sociais que se abriram no decorrer dos tempos.

Ainda, dada a transnacionalização do capital e seu sistema produtivo, o espaço e tempo de produção são revistos. Nascem e morrem regiões industriais ao longo do globo, buscando sempre as maiores taxas de lucro. O trabalhador, por sua vez transita aonde seus acessos the permitem, seja local, regional, nacional ou internacionalmente, nem sempre podendo acompanhar as melhores situações encontradas pelo capital.

Nesse contexto se enquadra a mudança de cidade de parte da confecção que Irene trabalhou, o que causou, segundo ela, um grande desgaste, já que residia a mais de $100 \mathrm{~km}$ de distância da filial de São Paulo. Para Harvey (2005, p. 177). A "redução das barreiras espaciais para o movimento de bens, pessoas, moedas e informações", reflexo da queda dos custos de transportes faz com que a qualidade do local ganhe importância na "competição" por alocar uma empresa:

Com a rendição das barreiras espaciais, a distância do mercado ou das matérias-primas se torna menos importante para as decisões localizadas [...]. As pequenas diferenças na oferta de mão-de-obra (quantidades e qualidades), nas infraestruturas e nos recursos, na regulamentação e tributação governamental assumem muito maior importância do que quando os custos elevados de transportes criavam monopólios "naturais" para a produção local em mercados locais (HARVEY, 2005, p. 177).

Sendo assim, vê-se a necessidade de oferecer condições atrativas para empresas se estabelecerem nas cidades, fomentando a concorrência entre localidades. O perigo mora quando os atrativos passam a ser, entre outras coisas, em detrimento das regulamentações trabalhistas e com a responsabilidade social da localidade. No caso de Irene, o desgaste do deslocamento somado ao baixo salário motivaram a sua saída da 
empresa. O trabalhador não conseguiu acompanhar os movimentos do capital.

\subsection{0 "TRABALHO INFORMAL"}

A informalidade do trabalho merece atenção neste artigo, uma vez que a ausência de direitos, sua instabilidade e precariedade tiveram, direta ou indiretamente, grande peso na vida de Irene.

Historicamente, o termo setor informal surge de um estudo realizado em 1972, no Quênia, pela Organização Internacional do Trabalho (OIT) a respeito da problemática do emprego (ALVES e TAVARES, 2006, p. 427). Na época se caracterizavam dois segmentos: o formal "caracterizado por unidades produtivas organizadas" e o informal "composto por unidades produtivas não organizadas", sendo que o informal se organizava produtivamente com pouco capital em "mercados não regulamentados e pouco competitivos" (CACCIAMALI, 1983 apud ALVES e TAVARES, 2006, p. 427).

Ainda segundo Alves e Tavares (2006, p. 427), a informalidade passa a ser estudada em análises sobre a América Latina e Caribe com questões relacionadas ao mercado de trabalho: emprego e desemprego, a partir dos anos de 1970, com as mesmas orientações da OIT, onde nela se agruparia "as categorias de trabaIhadores não subordinados à legislação trabalhista" e "atividades de baixo nível de produtividade" (CACCIAMALI, 1983 apud ALVES; TAVARES, 2006, p. 427). Ainda segundo os mesmos autores, faltava uma explicação da relação entre o setor informal e o funcionamento do sistema econômico.

Oliveira (2003, p. 71) diz que não é novo o que, no processo de industrialização brasileiro, desde a década de 1930, "veio a ser posteriormente chamado, pela literatura das instituições internacionais, 'setor informal'". Tanto que em seu ensaio de 1972, com o título "A economia brasileira: crítica à razão dualista", já tratava do tema (OLIVEIRA, s.d., p. 26), abordando as relações do chamado "setor informal" com o funcionamento do sistema econômico.

Oliveira (s.d., p. 25), a respeito do modelo de Colin Clark, desenvolvido na obra "The Conditions of economic progress" (1940 apud OLIVEIRA, idem, p. 25), categorizando o conjunto das atividades econômicas como setores Primário, Secundário e Terciário, diz que interpretações equivocadas podem confundir as relações formais entre esses setores, ou seja, "o papel que cada um desempenha no conjunto da economia [...] com o papel interdependente que jogam entre si" (OLIVEIRA, s.d., p. 26, destaque do autor). Ainda segundo Oliveira (Idem), interpretações de teóricos do subdesenvolvimento concluíram que uma das características do "modo de produção subdesenvolvido" é ter um setor terciário, ou de serviços, "inchado" na participação do produto e emprego, "que consome excedente e comparece como um peso morto na formação do produto".

Ao contrário das interpretações dos teóricos do subdesenvolvimento, de "inchaço" ou segmento "marginal", Oliveira (s.d, p. 27), vê que o crescimento do terciário "faz parte do modo de acumulação urbano adequado à expansão do sistema capitalista no Brasil":

[...] é uma questão estreitamente ligada à acumulação urbano-industrial. A aceleração do crescimento, cujo epicentro passa a ser a indústria, exige, das cidades brasileiras [...] infraestrutura e requerimentos em serviços para os quais elas não estavam previamente dotadas. A intensidade do crescimento industrial [...], não permitirá uma intensa e simultânea capitalização nos serviços, sob pena de esses concorrerem com a indústria propriamente dita pelos escassos fundos disponíveis para a acumulação propriamente capitalística. Tal contradição é resolvida mediante o crescimento não capitalístico do setor Terciário. [...] que 
não é contraditório com a forma de acumulação, que não é obstáculo à expansão global da economia, que não é consumidor de excedente. A razão básica pela qual pode ser negada a negatividade do crescimento dos serviços - sempre do ponto de vista da acumulação global é que a aparência de "inchação" esconde um mecanismo fundamental da acumulação: os serviços realizados à base de pura força de trabalho, que é remunerada a níveis baixíssimos, transferem, permanentemente, para as atividades econômicas de corte capitalista, uma fração do seu valor, "mais-valia" em síntese (OLIVEIRA, s.d., p. 29, grifos do autor).

Oliveira (s.d.), não estava analisando (inclusive), nada menos, do que se deu a conhecer por "informal". Indo ao encontro de suas análises, Alves e Tavares (2006) concordam que a economia "informal" faz parte do modo de acumulação capitalista:

Tal qual um assalariado, o produto de seu trabalho será enlaçado pela lógica do capital. O mercado é o ponto para o qual todos convergem e no qual todas as pseudo-autonomias se dissolvem. Por mais independente que o indivíduo imagine ser, o produto do seu trabalho terá, em algum momento, de se confrontar com outros, no mercado, onde cada troca imprime a presença da mais valia, expressando, portanto, a oposição do capital à capacidade viva de trabalho. (ALVES e TAVARES, 2006, p. 427).

Dessa forma, o "informal", fica sujeito aos movimentos capitalistas, sendo que "nas fases de expansão [...] aumentam-se os espaços de ocupação pelas atividades informais e nos momentos de crise essas atividades se retraem". (DEDECCA, 1990 apud ALVES e TAVARES, 2006, p. 427).

A situação de precariedade identificada na trajetória de Irene, como seu brechó, o carrinho de lanche ou mesmo os serviços de faxineira é agravada, uma vez que essas atividades, estão sujeitas aos movimentos capitalistas, que acompanham a perda do poder de compra dos trabalhadores assalariados (OLIVEIRA, 2003, p. 75). É bastante claro esse comportamento no que diz respeito aos trabalhadores domésticos, principalmente previamente ao que ficou conhecido como "PEC das domésticas" ${ }^{26}$. Essa situação ainda é agravada pela própria concorrência entre os que compõem esse quadro de informalidade.

A precarização do trabalho conhecido como "informal", ao contrário da ideia de "autonomia", é refletida diretamente na renda desses trabalhadores, marcados pela descontinuidade de suas atividades, "bicos", instabilidade e ausência de direitos.

Oliveira (2003, p. 30) afirma que o tipo de serviço chamado "informal", mais do que um "depósito do "exército industrial de reserva'", atua para "o processo da acumulação global e da expansão capitalista" reforçando a concentração de renda. Os "trabalhadores informais", como Irene, além de se submeterem às atividades econômicas capitalistas e sofrerem a precarização decorrente desse tipo de trabalho, por fim, ainda ficam à mercê do movimento de crescimento e estagnação da economia e do mercado de trabalho regulamentado, sem o mínimo amparo, como os direitos que, em tese, o emprego formal proporciona, além de estarem sujeitos à discriminação dependendo do trabalho que estiverem realizando no momento.

\section{CONSIDERAÇÕES FINAIS}

Machado (2014), ao investigar as trajetórias de vida dos sujeitos que residiram na Ocupação Pinheirinho, encontra alguns acontecimentos comuns a todos os seus entrevistados, compondo múltiplas determi-

26 Nome popular dado à Proposta de Emenda Constitucional no 66 de 2012, criando a Emenda Constitucional no72, visando equiparar parte dos direitos e deveres dos trabalhadores domésticos às demais categorias de trabalhadores. 
nações para um ponto de inflexão na vida desses sujeitos, vendo na Ocupação uma alternativa de moradia. Dentre os relatos contidos em Machado (2014), optou-se neste artigo, por um olhar para a influência do trabalho na escolha desses sujeitos por uma ocupação urbana. Para isso, utilizou-se o rico depoimento de Irene, por conter temas comuns a outros depoimentos em Machado (2014).

Inicia-se o artigo descrevendo uma cena do dia a dia de Irene dentro da ocupação, no intuito de, além de contextualizar como passou a ser sua vida, levar o leitor a criar uma imagem inicial de Irene. Seria essa mulher uma oportunista, "mau-caráter", predisposta à "negócios duvidosos/nebulosos"?

Entendendo que "O concreto é concreto porque é síntese de muitas determinações, isto é, unidade no diverso" (MARX, 1979, p. 63), busca-se na trajetória de trabalho de Irene, algumas destas determinações.

Verifica-se, dessa maneira, todo um histórico de trabalhos precários marcando sua vida e colocando outros trabalhos, igualmente precários, como opção imediata para garantir sua renda, no limite de uma ocupação urbana se tornar realidade para a redução de seus gastos. É inegável o peso do trabalho como uma força estruturante em sua vida. De maneira simplista, em um universo de influencias que possibilitaram a lanchonete descrita da Cena 1, destaca-se a influência de sua experiência com um carrinho de lanche, que por sua vez, teve influência de sua experiência em um bar. Sua opção de moradia pela ocupação Pinheirinho, deu-se pelo baixo salário e condições de trabalho em uma confecção. O emprego em uma confecção, por sua vez, deu-se a partir da experiência de um brechó em sua casa. Tanto o carrinho de lanche como o brechó em sua casa, no entanto, foram alternativas para complementar sua renda nos dias livres de um trabalho de faxineira que realizava. Suas experiências anteriores repetem esse roteiro de trabalhos precários.

Como nos lembra Marx, "Os homens fazem a sua própria história, mas não a fazem arbitrariamente, nas condições escolhidas por eles, mas antes sob as condições diretamente herdadas e transmitidas pelo passado" (1971, p. 15).

Assim sendo, é preciso cuidado ao olhar a Cena 1. Ao conhecer a trajetória de trabalho de Irene, vê-se a importância de conhecer as diversas influencias em inúmeros contextos, mesmo em ambientes mais distantes. Acredita-se dessa maneira que, apresentada a Cena 2, seja possível ao leitor reinterpretar a Cena 1 pois, "Para conhecer realmente um objeto, é preciso apanhar e estudar todos os seus aspectos, todas as suas ligações e mediações. [...]. a lógica dialética exige que se considere um objeto em seu desenvolvimento, seu "movimento próprio" (como o diz às vezes Hegel), sua transformação [...]" (LENIN apud FERNANDES, 7978, p.28).

\section{REFERÊNCIAS}

AÇÃO policial em Pinheirinho repercute na mídia internacional. Sul21. Porto Alegre, jan. 2012. Disponível em: <http:// www.sul21.com.br/jornal/acao-policial-em-pinheirinho-repercute-na-midia-internacional/>. Acesso em: 25 out. 2014.

ALVES, X. Empreiteira abandona obras do Pinheirinho dos Palmares. O Vale. São José dos Campos, SP, 19 mar. 2015. Disponível em < http://www.ovale.com.br/empreiteira-abandona-obras-do-pinheirinho-dos-palmares-1.580715>. Acesso em 22 mar. 2015.

ALVES, M.; TAVARES, M A. A dupla face da informalidade do trabalho: autonomia ou precarização. In: ANTUNES, R. (Org.). Riqueza e miséria do trabalho no Brasil. São Paulo: Boitempo, 2006.

ANDRADE, I. C. D. Movimento social, cotidiano e política: uma etnografia da questão indenitária dos sem-teto. 2010. Dissertação (Mestrado em Antropologia Social - Universidade de São Paulo, São Paulo. Disponível em: <http://www. teses.usp.br/teses/disponiveis/8/8134/tde-10112010-110021/es.php>. Acesso em: 04 fev. 2012.

ANTUNES, R. As mutações do mundo do trabalho na era da mundialização do capital. Educação e Sociedade, São 
Paulo, v. 25, p. 335-351, 2004.

BORGES, T. Pelo mundo, brasileiros protestam contra a desocupação do Pinheirinho. Opera Mundi. São Paulo, fev. 2012. Disponível em: <http://operamundi.uol.com.br/conteudo/noticias/19667/pelo+mundo+brasileiros+protestam+contra+a+desocupacao+do+pinheirinho.shtml>. Acesso em: 25 out. 2014.

BRISOLA, E. M. A. Estado penal, criminalização da pobreza e Serviço Social. Ser Social (UnB), v. 14, p. 127-154, 2012.

CARDOSO. R. Aventuras de antropólogos em campo ou como escapar das armadilhas do método. In: CARDOSO, R. (Org.). A aventura antropológica: Teoria e pesquisa. 4. Ed. Rio de Janeiro: Paz e Terra, 2004

CONDEPE Conselho Estadual de Defesa dos Direitos da Pessoa Humana - São Paulo. São Paulo, 2012

COSTA, A. Preço dos imóveis dobra em S. José em três anos, diz Creci. O Vale. São José dos Campos, SP, 18 set. 2011. Disponível em: <http://www.ovale.com.br/nossa-regi-o/preco-dos-imoveis-dobra-em-s-jose-em-tres-anos-diz-creci-1.158678>. Acesso em: 22 abr. 2012.

EM PROTESTO, EX-MORADORES DO PINHEIRINHO FAZEM OCUPAÇÃO-RELÂMPAGO POR 2 HORAS. Brasil de Fato. São Paulo, jul. 2013. Disponível em: <http://www.brasildefato.com.br/node/13681>. Acesso em: 25 out. 2014.

FELTRAN, G. S. Vinte anos de PCC em São Paulo: o espaço entre governo e crime. Le Monde Diplomatique Brasil, São Paulo. 2013. Disponível em <http://www.diplomatique.org.br/artigo.php?id=1351>. Acesso em: 15 abr. 2013.

FERNANDES, F. (Org.). Lenin. São Paulo: Ática, 1978.

FORLIN, L. C. COSTA, M. F. Urbanização e segregação sócio-espacial na cidade de São José dos Campos-SP: o caso Pinheirinho. Geosul, Florianópolis, v. 25, n. 49, p 123-158, jan./jun. 2010.

GROULX, L. H. Contribuição da pesquisa qualitativa à pesquisa social. In: POUPART, J. M. et al. A pesquisa qualitativa: enfoques epistemológicos e metodológicos. 3 ed. Petrópolis, RJ: Vozes, 2012

HARVEY, D. A produção capitalista do espaço. 2. ed. São Paulo: Annablume, 2005.

IANNI, O. (org.). Marx. São Paulo: Ática. 1979

IBGE. Censo Demográfico 2010 - Resultados do universo. Disponível em: <http://www.ibge.gov.br>. Acesso em: 22 out. 2012.

MACHADO, P.H.F. Pinheirinho entre o sonho e a realidade: Experiências em uma Ocupação Urbana na cidade de São José dos Campos - SP. Dissertação (Mestrado em Desenvolvimento Humano: Formação, Políticas e Práticas Sociais) Universidade de Taubaté, Taubaté, SP, 2014.

MARX, K. "Prólogo", in: 018 Brumário de Louis Bonaparte. Coimbra: Nosso Tempo, 1971.

. Contribuição à crítica da economia política. In: Textos 3. Alfa-Omega: São Paulo, 1979.

MINISTÉRIO DAS CIDADES, 2009. Plano Nacional de Habitação. 2009. Disponível em <http://www.cidades.gov.br/images/stories/ArquivosSNH/ArquivosPDF/Publicacoes/Publiicacao_PlanHab_Capa.pdf >. Acesso em 25 de out. 2014.

NEPO (Núcleo de Estudos de População/ Unicamp). Atlas de condição de vida em São José dos Campos, 2003

O PIB dos municípios paulistas em 2009. Fundação SEADE. Disponível em <http://www.seade.gov.br/produtos/pibmun/pdfs/PIBMunicipal_2009.pdf>. Acesso em: 22. jun. 2012.

OLIVEIRA, F. A economia brasileira: crítica à razão dualista. s.l. s.d.. Disponível em: <http://www.cebrap.org.br/v2/ files/upload/biblioteca_virtual/a_economia_brasileira.pdf>. Acesso em: 10 maio 2013.

. O Elo Perdido: Classe e identidade de classe na Bahia. São Paulo: Fundação Perseu Abramo, 2003

Política numa era de indeterminação: opacidade e reencantamento. In: OLIVIRA, F (Org.) ; RIZEK, C. S. (Org.) . A Era da Indeterminação. 1. ed. São Paulo: Boitempo Editorial, 2007.

PEREIRA, C. Maioria dos eleitores apoia a desocupação do Pinheirinho. O Vale. São José dos Campos, 2012. Disponível em < http://www.ovale.com.br/nossa-regi-o/maioria-dos-eleitores-apoia-a-desocupac-o-do-pinheirinho-1.216536>. Acesso em 25 out. 2014.

PDDI-2006. Plano Diretor de Desenvolvimento Integrado, PDDI 2006 - Diagnóstico. São José dos Campos: PMSJC, 
2006.

SANTOS, C. Dilma autoriza construção de casas para ex-moradores do Pinheirinho. G1. Vale do Paraíba e Região, SP, 25 mar. 2014. Disponível em: <http://g1.globo.com/sp/vale-do-paraiba-regiao/noticia/2014/03/dilma-autoriza-obras-de-residencial-para-ex-moradores-do-pinheirinho.html>. Acesso em 20 abr. 2014.

TELLES, V. S. A cidade nas fronteiras do legal e ilegal. Belo Horizonte: Argumentum, 2010

TEODORA, C. Ex-moradores do Pinheirinho completam um mês em abrigos. O Vale. São José dos Campos, 2012. Disponível em < http://www.ovale.com.br/nossa-regi-o/ex-moradores-do-pinheirinho-completam-um-mes-em-abrigos-1.222221>. Acesso em 25 out. 2014. 